\title{
Super Majoritarianism and the Endowment Effect*
}

\author{
Uriel Procaccia $^{\dagger}$ and Uzi Segal
}

March 18, 2002

\begin{abstract}
The American and some other constitutions entrench property rights by requiring super majoritarian voting as a condition for amending or revoking their own provisions. Following Buchanan and Tullock [5], this paper analyzes individuals' interests behind a veil of ignorance, and shows that under some standard assumptions, a (simple) majoritarian rule should be adopted. This result changes if one assumes that preferences are consistent with the behavioral phenomenon known as the "endowment effect." It then follows that (at least some) property rights are best defended by super majoritarian protection. The paper then shows that its theoretical results are consistent with a number of doctrines underlying American Constitutional Law.
\end{abstract}

*We wish to thank Jennifer Arlen, Ehud Kamar, Daniel Klerman, John McGinnis, Joe Ostroy, Edward Rock, David Rudenstine, Alan Schwartz, Menny Shalom, Dan Simon, Stewart Sterk, and Dan Vincent for helpful comments on previous drafts.

${ }^{\dagger}$ Hebrew University School of Law, Jerusalem 91905, Israel. E-mail: msurpro@ mscc.huji.ac.il

${ }^{\ddagger}$ Department of Economics, Boston College, Chestnut Hill MA 02467. E-mail: segalu@bc.edu 


\section{Introduction}

Parts of the legal system can be interpreted as an allocation of property rights among different claimants. Such an allocation can, and often is, put in place by regular statutes as well as by decisional law. Certain property entitlements, however, are constitutionally entrenched. Thus, the Fifth Amendment of the American Constitution protects certain property rights of the citizens and forbids the government from taking them without just compensation. By entrenching these property rights within the Constitution, the citizenry denies itself the opportunity to change course and reshuffle entitlements by majoritarian resolution. The process of Constitutional amendment commits the citizenry to the arduous path of super majoritarian regulation. Some other constitutions, like those of Germany, The Netherlands, and Spain, offer similar protection. ${ }^{1}$ In this paper we want to offer a decision theoretic explanation to this phenomenon.

The most important contribution to understanding constitutional entrenchment of property rights was offered by Buchanan and Tullock [5]. They suggested to analyze rules for future redistributions by positioning a set of players behind a veil of ignorance. Acting in their own personal interests, members of society are threatened with the possibility of a future majority taking away from them something which is theirs; or not wishing to give them something that they do not currently own. The expected cost of the first contingency is declining with the number of voters necessary for its attainment, while the expected cost of the second contingency is increasing with the number of voters. Let $n$ be the number of players. If the minimum of the aggregate cost function is obtained at a number $k>\frac{n}{2}+1$, this may serve as a normative justification for the super majoritarian constitution. The problem with this analysis is that there is nothing in it to suggest that the ideal number, $k$, is larger than a simple majority. It is, perhaps, the realization of this fact that caused a decline in the influence of Buchanan and Tullock's work (see Tullock [19]).

Following Buchanan and Tullock, we too discuss a model where a set of subjects are positioned behind a veil of ignorance. We assume that these subjects know their preferences, but not their future endowments. We prove in Section 2 that under a standard assumption of risk aversion, these sub-

\footnotetext{
${ }^{1}$ Germany: Section 14(3); The Netherlands: Section 14(1); Spain: Section 33(3).
} 
jects would prefer future society to adopt fully egalitarian principles. We then show that this result can be obtained by adopting a simple majoritarian rule, i.e., without a super majoritarian constitution. In other words, according to these assumptions, super majoritarian protection of property rights is suboptimal. The main contribution of our paper is to show (in Section 3) that this analysis does not hold if we assume that preferences are consistent with the behavioral phenomenon known as the "endowment effect." This effect records a gap between what subjects are willing to accept, as their minimum price, for parting with something that is already theirs, and what they are willing to pay, as their maximum price, for the same object, if they do not already possess it. Numerous experiments show that for most subjects, the former far exceeds the latter. This is consistent with the hypothesis that subjects develop a special sense of attachment to their existing endowment. However, this difference exists only in tangible objects intended for personal consumption and not in monetary wealth or other forms of fungible or tradable goods. $^{2}$

It follows from the analysis of Section 2 that if all wealth were defined in cash and tradable commodities, the case for constitutional entrenchment of property rights would have been rather unclear, and under some plausible assumptions, no entrenchment would have been optimal. But as we show in Section 3, assuming the endowment effect, the case for constitutional entrenchment becomes stronger as a measure of protecting endowed property.

To illustrate our claims by means of an example, we then turn to show that the American Constitution consistently applies super majoritarian voting rules to protect tangible entitlements in property rights, but fails to extend the same protection to general wealth (money) in which no gap exists between the willingness to accept and the willingness to pay (see Section 4). Furthermore, we show that the constitutional protection of wealth in America is constantly shifting, in tandem with the composition of typical asset-portfolios in different historical periods. When most people held their wealth in tangible assets with little trading activity, the protection of property rights offered by the American Constitution reached its apex. When wealth became more concentrated in cash, corporate securities and other

\footnotetext{
${ }^{2}$ For analysis of this phenomenon and some experimental evidence, see Thaler [18], Kahneman and Tversky [10], Tversky and Kahneman [21, 22], Beteman et. al. [2], and Knetsch and Sinden [11].
} 
tradable or negotiable goods, this protection lost ground.

There are many other explanations of the super-majoritarian requirement, at least in its American version. Tushnet [20], Sunstein [17], and Przeworski [14] explain that the Constitution was intended to secure to its drafters, a distinct class of land and slave owners, a measure of protection for their vested interests, without which the initial passage of the constitution could not have been secured. Black [4] argues that the Constitution is not really counter majoritarian, because it adapts itself to the changing mores of time, and thus reflects the true will of the constituency in every given generation. Strauss [16] claims that the constitutional amendment process is completely illusory, as all important modifications of the existing Constitution are judge-made, while formal amendments are nothing but ratifications of the more profound changes already forged within the body politick. Olson [12] claims that minorities often possess an inordinately strong influence on the legislative process, given their tight organization and lower costs of forming winning coalitions. From this it can be inferred that super majorities are needed to overcome minority clout, and to bar simple majorities from acting against the interests of their own constituencies. Finally, Cooter [6] made a recent attempt to explain the Constitution in game theoretic terms, arguing that a simple majority is always a coreless solution; each given distribution is dominated by a majority of players who have an incentive to toss the system into an endless cycle of changes, thereby creating economic instability and political chaos.

We do not wish to claim that these explanations are not valid. Moreover, our analysis clearly ignores important issues like the discouraging effect of egalitarianism on individual incentives to generate wealth (see Section 5 below). However, we want to show that certain kinds of super majoritarianism are compatible with recent developments in the decision theoretic literature. Rather than viewing our paper as an exclusive explanation for the entrenchment of some property rights, we wish to emphasize its conformity with the modern decision theoretic literature. As suggested in Section 4, this added explanation has a surprisingly good fit with some major trends in the historical development of American constitutional law. 


\section{Selfish Voters and Future Utilitarianism}

In this section we show that although individuals may be assumed to act selfishly, there are circumstances in which it is rational for all of them to seek an egalitarian social outcome.

Suppose society has $n$ members, living for two periods, the present (period 1 ) and the future (period 2), and suppose that there are $k$ commodities. Individuals do not know their future endowments, and evaluate uncertain outcomes by using an expected utility functional $V$, where for $\tilde{x}=$ $\left(x_{1} ; p_{1} ; \ldots ; x_{m}, p_{m}\right), x_{1}, \ldots, x_{m} \in \Re^{k}, V(\tilde{x})=\sum_{s} p_{s} u\left(x_{s}\right)$, with a utility function $u: \Re^{k} \rightarrow \Re$. We assume that $V$ satisfies risk aversion in the sense that the average of a non-degenerate distribution is strictly preferred to the distribution itself.

Risk Aversion: Let $\tilde{x}=\left(x_{1} ; p_{1} ; \ldots ; x_{m}, p_{m}\right)$, where $x_{1}, \ldots, x_{m} \in \Re^{k}$. Then $(\mathrm{E}[\tilde{x}], 1) \succeq \tilde{x}$, where $\mathrm{E}[\tilde{x}]=\sum_{s} p_{s} x_{s}$, and indifference is obtained only if $\tilde{x}=(x, 1)$.

At period 1, person $i$ is facing three sources of uncertainty. He does not know what future social resources will be available, nor does he know the allocation of possible social endowments among individuals. Moreover, he does not know what will be his position in each possible future society. That is, he does not know what part of the social resources of any future realization he will possess. We restrict this third source of uncertainty, and assume that his beliefs are that he has an equal chance to be any member of future society. That is, he believes that whatever the future social resources and allocation will be, with probability $\frac{1}{n}$ he will receive each of the social allocation's $n$ possible bundles.

Formally, he has a probability distribution over future resources and their allocations, and conditional on the realization of allocation $\omega^{2}=\left(\omega_{1}^{2}, \ldots, \omega_{n}^{2}\right)$ he believes he has $\frac{1}{n}$ chance of receiving each of the bundles $\omega_{j}^{2}$ (where for every $\left.j, \omega_{j}^{2} \in \Re^{k}\right)$. A social policy is a reallocation of these goods, that is, an allocation of the form $\left(x_{1}^{2}, \ldots, x_{n}^{2}\right)$ such that $\sum x_{j}^{2}=\sum \omega_{j}^{2} \cdot{ }^{3}$ It follows from the properties of expected utility theory that regardless of other possible

\footnotetext{
${ }^{3}$ We assume here that the reallocation mechanism is not wasteful. Otherwise, one can only assume $\sum x_{j}^{2} \leqq \sum \omega_{j}^{2}$ (for $x, y \in \Re^{k}, x \leqq y$ means that for every $m=1, \ldots, k$, $\left.x^{m} \leqslant y^{m}\right)$. See section 5 bellow.
} 
realizations of future social endowments and their likelihood, person i prefers, in period 1 , that society should select, in period 2 , a distribution $\left(x_{1}^{2}, \ldots, x_{n}^{2}\right)$ that maximizes his expected utility $V_{i}\left(x_{1}^{2}, \frac{1}{n} ; \ldots ; x_{n}^{2}, \frac{1}{n}\right)$. By risk aversion, this is the egalitarian distribution, the one that gives everyone $\frac{1}{n} \sum \omega_{j}^{2}$. In other words, if person $i$ could decide in period 1 what allocation society should adopt in the future, he would have selected the egalitarian distribution, the one that gives everyone the same bundle of commodities. Moreover, he would like society to choose this allocation in all possible realizations of its future endowments. ${ }^{4}$

The same holds true for everyone else in society. That is, even though individuals $i$ and $j$ may have different preferences and different beliefs about aggregate future wealth and its distribution, they will nevertheless agree that given their present selfish preferences, it is best for future society to reallocate future wealth in an egalitarian manner. This is true even if they have different beliefs about the level of the future average income.

Note the importance of the assumption that individuals believe that all the $n$ possible future wealth distributions are equally likely for themselves. Without it, it is not necessarily true that the average income is superior to the distribution. One may object to this assumption by claiming that even though most type wealthier persons realize that their luck may run its course (and if they are poor, Fortune may still grace their future), wealthy persons and their descendants are more likely to remain wealthier than poor people and their offspring, and our symmetry assumption may well be violated. However, if this is the case, and if each person wishes to maximize his stake in the future, the rich should be interested in entrenching their riches and the poor should be interested in wealth redistribution. Assuming that the latter outnumber the former, it is hard to see why the majority of voters consent to constitutional entrenchments of property rights in the first place.

There is a difference between this kind of egalitarian principle and some alternative theories of justice that depend on utilities. Harsanyi [7] suggested axioms leading to the utilitarian social welfare function $\sum u_{i}$, while Rawls [15] suggested $\max \min \left\{u_{i}\right\}$. To be sure, if all individuals in society have the same utility function $u$, then both Harsanyi's and Rawls' social

\footnotetext{
${ }^{4}$ This is not true if preferences are not expected utility. In that case it may happen that even if the decision maker is risk averse, the conditional averages will be dominated by the original distribution. This is of course not the case if there is only one possible future distribution.
} 
welfare functions are maximized at the egalitarian distribution. We, on the other hand, do not need to assume that all individuals have the same utility function to obtain the desirability of the egalitarian solution, and our focus of attention is not individual utilities, but income levels. Moreover, and this is the major difference between the present analysis and standard models of social choice, individuals in our model are motivated by selfishness and not by social justice. All the calculations of individual $i$ are made with respect to his (known) utility function $u_{i} .{ }^{5}$ The only two assumptions needed are symmetry regarding beliefs about future income distribution, and risk aversion.

We have shown that under our assumptions, selfish individuals living in the present would wish future social decision makers to act as if they were guided by an egalitarian principle. But how can they achieve this purpose? We now add an axiom under which a future set of decision-makers will satisfy egalitarian desiderata by effecting transfers by a simple majority vote. The meaning of this result is that no current entitlement should ever be entrenched, or, in other words, a constitutional protection of property rights against taking is not needed. This result will be re-examined as we relax the axioms in the subsequent section.

We defer to a latter section the question whether it is advisable for society to actually reach an egalitarian distribution, and deal here only with the question of how can society reach such a distribution if it desires to do so. The problem is that future voters are not bound by their previous preferences. In other words, once they know who they are, it is no longer true that decision makers prefer the average bundle to their actual holding, even if they are risk averse. In fact, it may even happen that everyone will strictly prefer his holding to the average bundle. For example, suppose $n=k=2$, and let person 1 have the nonstochastic utility function $u_{1}\left(x^{1}, x^{2}\right)=x^{1}+2 x^{2}$ and the bundle $(1,3)$, and let person 2 have the utility function $u_{2}\left(x^{1}, x^{2}\right)=2 x^{1}+x^{2}$ and the bundle $(3,1)$. Both prefer their holding to the average $(2,2)$. To prevent such examples, we assume that the endowments of more than half of the population is less, in all commodities, than the social average. Formally:

Skewed Distributions The number of individuals $i$ whose allocation $\omega_{i}^{2}$ satisfies $\omega_{i}^{2} \leqq \bar{\omega}^{2}=\frac{1}{n} \sum \omega_{j}^{2}$ is more than $\frac{n}{2}$.

\footnotetext{
${ }^{5}$ The importance of this point becomes evident in Section 3 below.
} 
For empirical evidence supporting this assumption see Atkinson [1]. It holds for income, and more significantly, for wealth distribution.

Suppose that in the second period, when they know how wealthy they are, individuals are selfish. It follows that when asked to vote whether or not they would like society to impose the egalitarian distribution $\bar{\omega}^{2}$, person $i$ will vote favorably iff $\omega_{i}^{2} \leqq \bar{\omega}^{2}$. Since more than half of the population satisfies this condition, if follows that a simple majority rule will imply egalitarian income distribution in the next period.

Our structure does not imply that society will necessarily reach an egalitarian distribution. Suppose for example that society is composed of three members, and there is one good only. The initial distribution of this good is given by $\omega=(11,4,0)$. A majority of selfish individuals will vote in favor of replacing this distribution with $\tilde{\omega}=(7,6,2)$. Once this new distribution is obtained, no simple majority will ever vote for the egalitarian distribution $(5,5,5)$. We do not claim that majority rule necessarily leads to an egalitarian distribution, and we do not claim that there are no social mechanisms that may lead to such a future allocation. What we do claim is the following. Under the constraint that future societies can vote to reallocate their resources, but face severe difficulties in changing the voting rules themselves, the only majoritarian rule under which the egalitarian distribution may win regardless of the actual initial distribution of social resources (subject to the skewed distributions assumption) is the simple majority rule. For any other special majority rule, one can find a distribution of the social resources that will not be replaced by the egalitarian distribution even after many rounds of voting. Suppose we impose a $0.5+\varepsilon$ majority rule. Assume for simplicity one good only, and consider the initial distribution where $0.5+\frac{\varepsilon}{2}$ of the population receive $a$, while the remaining $0.5-\frac{\varepsilon}{2}$ of the population receive $b>a$. Assuming that the only relevant parameter for a reallocation is personal wealth, no money can be taken from either group, as it can blocked by more than $0.5-\varepsilon$ of the population. 


\section{The Endowment Effect and the Entrenched Constitution}

Under the assumptions we outlined in the previous section, future simple majority enables society to reach what at present everyone considers to be the best outcome. In other words, no special voting devices are needed to entrench property rights, and they should not be secured beyond the measure of protection they receive by the simple majority rule. But this conclusion may change once we introduce the possibility of more general preferences for uncertain prospects.

The psychological literature documents the existence of what came to be known as the "endowment effect." Tversky and Kahneman [21] suggested that preferences over bundles of commodities should depend on a reference point. Formally, preferences over $\Re^{k}$ given the reference point $y$ should be denoted $\succeq_{y}$ and the utility function representing these preferences $u(\cdot \mid y)$. Their main definition and assumption regarding the endowment effect is the following:

Loss Aversion Let $x, y, r, s \in \Re^{k}$ such that for $\operatorname{good} \ell, s^{\ell}=y^{\ell}>r^{\ell}=x^{\ell}$, and for all $m \neq \ell, r^{m}=s^{m}$. Then $y \succeq_{r} x$ implies $y \succ_{s} x$.

The intuition is clear. If, when having as a reference point $r$, with the lower quantity of good $\ell$, the decision maker was willing to exchange $y^{-\ell}$ for $x^{-\ell}$ so that the quantity of good $\ell$ will increase from $x^{\ell}$ to $y^{\ell}$, then he would certainly be willing to keep $y^{-\ell}$ over $x^{-\ell}$ so that the quantity of good $\ell$ will not decrease from $y^{\ell}$ to $x^{\ell}$ when the reference point is $s$ with the higher level of good $\ell{ }^{6}$ For a further discussion of this phenomenon, experimental evidence, and axiomatization, see Thaler [18], Kahneman and Tversky [10], Tversky and Kahneman [21, 22], Beteman et. al. [2], and Knetsch and Sinden [11]. As is evident from Tversky and Kahneman [21], this effect relates to goods, and not to money. ${ }^{7}$ We show now how the endowment effect may change the desirability of simple majoritarian rules.

\footnotetext{
${ }^{6} x^{-\ell}$ stands for $\left(x^{1}, \ldots, x^{\ell-1}, x^{\ell+1}, \ldots, x^{k}\right)$.

${ }^{7}$ Strictly speaking, this effect is stronger with respect to goods than with respect to money. The experiment reveals higher asking monetary price for endowed goods than the price subjects are willing to pay to purchase the same goods.
} 
For our purposes, we assume that there are two goods, money $(\mathrm{m})$ and land $(x)$, and that the utility function is of the form $V(m, x)=v(m)+$ $u(x \mid y)$, meaning that if the decision maker's current holding of land is $y$, then he evaluates $x$ with the value obtained from $u(x \mid y)$. We will assume the following.

1. $v$ is concave, and for every $y, u(\cdot \mid y)$ is concave.

2. $u(x \mid y)$ has a kink at the point $x=y$.

3. Let $y<y^{\prime}$ be two reference points. For $x<y<y^{\prime}, u(x \mid y)=u\left(x \mid y^{\prime}\right)$, and for $x>y^{\prime}>y, u\left(x \mid y^{\prime}\right)=u(x \mid y)+\left[u\left(y^{\prime} \mid y^{\prime}\right)-u\left(y^{\prime} \mid y\right)\right]$. Moreover, for $x \in\left(y, y^{\prime}\right), u^{\prime}\left(x \mid y^{\prime}\right)>u^{\prime}(x \mid y)$ (see Fig. 1).

The first assumption, that $u(x \mid y)$ is concave, is directly implied by risk aversion. The second assumption implies a significant difference between gains and losses. Not only is it true, as follows by the concavity of $u$, that gaining a certain amount $\varepsilon$ of land generates less utility than the the drop in utility when $\varepsilon$ is lost, but this holds even for infinitesimally small quantities of land.

The third assumption suggests that changing the reference point from $y$ to $y^{\prime}$ affects marginal utility (from land) only for outcomes between $y$ and $y^{\prime}$. (In Fig. 1, the utilities $u(\cdot \mid y)$ and $u\left(\cdot \mid y^{\prime}\right)$ coincide up to $y$, and parallel beyond $\left.y^{\prime}\right)$. Also, this assumption implies that $u^{\prime}\left(y^{-} \mid y\right)$ and $u^{\prime}\left(y^{+} \mid y\right)$ are decreasing functions of $y$. That is, the marginal utility from a small gain that is added to the endowment is decreasing with the size of the endowment, and the marginal loss in utility from a small increment taken away from the endowment is decreasing with the size of the endowment. In other words, the damage from losing $\varepsilon$, measured in terms of utility, is less severe to the rich than it is to the poor. Similarly, the gain in utility from winning $\varepsilon$ is larger to the poor than to the rich. We explain the implications of this assumption in Section 5 below.

Functions satisfying these three requirement are consistent with the loss aversion assumption. Formally:

Lemma 1 If the function $V(m, x)$ satisfies the above three assumptions, then the preferences represented by this function satisfy loss aversion. 


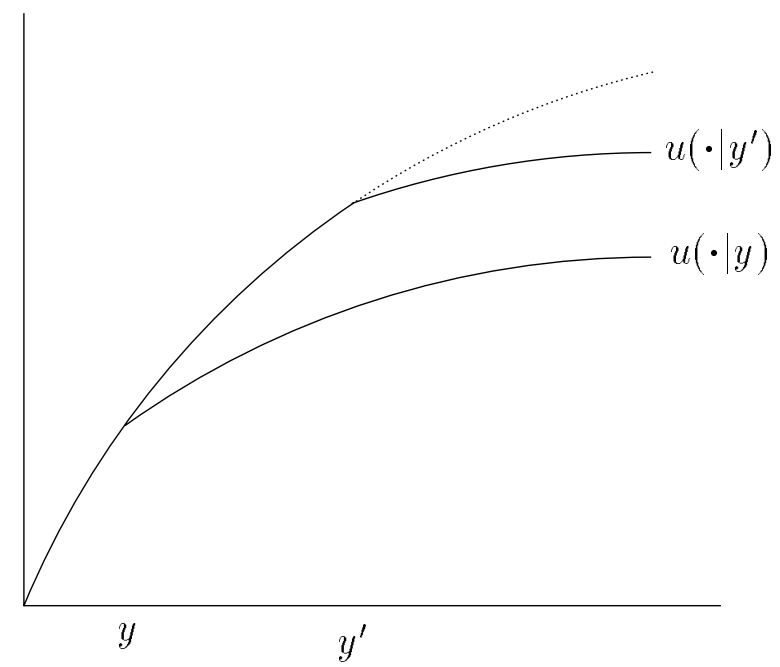

Figure 1: Assumption 3

Proof We want to show that if $y>x$ and $V\left(m, y \mid m^{\prime \prime}, x\right) \geqslant V\left(m^{\prime}, x \mid m^{\prime \prime}, x\right)$, then $V\left(m, y \mid m^{\prime \prime}, y\right)>V\left(m^{\prime}, x \mid m^{\prime \prime}, y\right)$. But $V\left(m, y \mid m^{\prime \prime}, x\right)=v(m)+u(y \mid x)$, $V\left(m^{\prime}, x \mid m^{\prime \prime}, x\right)=v\left(m^{\prime}\right)+u(x \mid x), V\left(m, y \mid m^{\prime \prime}, y\right)=v(m)+u(y \mid y)$, and $V\left(m^{\prime}, x \mid m^{\prime \prime}, y\right)=v\left(m^{\prime}\right)+u(x \mid y)$. Now $V\left(m, y \mid m^{\prime \prime}, x\right) \geqslant V\left(m^{\prime}, x \mid m^{\prime \prime}, x\right)$ implies $v(m)+u(y \mid x) \geqslant v\left(m^{\prime}\right)+u(x \mid x)$, hence $v\left(m^{\prime}\right)-v(m) \leqslant u(y \mid x)-u(x \mid x)$. By assumption, $u(y \mid x)-u(x \mid x)<u(y \mid y)-u(x \mid y)$, hence $v(m)+u(y \mid y)>$ $v\left(m^{\prime}\right)+u(x \mid y)$, and it follows that $V\left(m, y \mid m^{\prime \prime}, y\right)>V\left(m^{\prime}, x \mid m^{\prime \prime}, y\right)$.

Consider now once again the optimization problem faced by individual $i$ during the first period. He doesn't know what will be the social endowments in the next period, nor does he know the distribution of these endowments. But whatever these will be, he believes that he has an equal chance of being any of the $n$ members of society. Once the actual distribution is known, society will reallocate its resources, so that the individual who is initially allocated $\omega_{j}^{2}$ will receive $x_{j}^{2}\left(\omega_{j}^{2}\right)$ instead. The budget constraint is $\sum x_{j}^{2}\left(\omega_{j}^{2}\right)=$ $\sum \omega_{j}^{2}$. For simplicity, we omit the second period superscript. The question now is, what allocation $\left(x_{1}\left(\omega_{1}\right), \ldots, x_{n}\left(\omega_{n}\right)\right)$ would person $i$ like future society to choose?

It is possible to argue that there should be no difference between the analysis of Section 2 and the analysis of the present situation, as the relevant 
reference point should be the decision maker's current holding. At period 1, when individual $i$ knows his current endowment, and is trying to evaluate future uncertainty, he acts as an expected utility maximizer (albeit with a non-differential utility at his current holding), hence we should still obtain the same result, namely, that a simple majority rule is optimal. But this argument ignores the fact that once the decision maker realizes actual future distribution of social endowments, his actual bundle of commodities will define his reference point. Therefore, when selecting a constraints on future social policies, this new reference point should be considered. Since he is an expected utility maximizer, his analysis of each possible realization of social endowments is separable from other possible realizations. We turn now to spell out individual i's optimal strategy, assuming his familiarity with the distribution of future endowments but ignorance of his own.

Unlike standard analysis of uncertainty with reference points, where the decision maker knows his reference point but not the outcome he will receive, in this case his major source of uncertainty is his reference point. Once this uncertainly is resolved, he knows his outcome as well. We therefore suggest that each decision maker would be interested in maximizing his expected utility-gain (which may, in fact, be negative). Formally, let $\omega_{j}=\left(m_{j}^{\prime}, y_{j}\right)$, $j=1, \ldots, n$ be a possible realization and allocation of future endowments. Individual $i$ prefers future society to choose the allocation

$$
\left(\left(m_{1}\left(\omega_{1}\right), x_{1}\left(\omega_{1}\right)\right) \ldots,\left(m_{n}\left(\omega_{n}\right), x_{n}\left(\omega_{n}\right)\right)\right.
$$

that is, to replace each of his possible future bundles $\omega_{j}=\left(m_{j}^{\prime}, y_{j}\right)$ with $\left(m_{j}\left(\omega_{j}\right), x_{j}\left(\omega_{j}\right)\right)$, where the vector in eq. (1) solves

$$
\begin{array}{ll}
\max & \sum_{j} \frac{1}{n}\left[V_{i}\left(m_{j}\left(\omega_{j}\right), x_{j}\left(\omega_{j}\right) \mid \omega_{j}\right)-V_{i}\left(m_{j}^{\prime}, y_{j} \mid \omega_{j}\right)\right] \\
\text { s.t. } & \sum_{j} x_{j}\left(\omega_{j}\right)=\sum_{j} y_{j} \\
& \sum_{j} m_{j}\left(\omega_{j}\right)=\sum_{j} m_{j}^{\prime}
\end{array}
$$

Here $V_{i}\left(m_{j}\left(\omega_{j}\right), x_{j}\left(\omega_{j}\right) \mid \omega_{j}\right)$ is the utility of person $i$ from the bundle $\left(m_{j}, x_{j}\right)$ that will be reallocated to him if his true second period outcome is $\omega_{j}$, given the reference point $\omega_{j}$. From this we subtract $V_{i}\left(m_{j}^{\prime}, y_{j} \mid \omega_{j}\right)=V_{i}\left(\omega_{j} \mid \omega_{j}\right)$, which is his utility from the outcome $\omega_{j}$ with the same reference point. Note 
that expected utility implies separable analysis of each possible realization of second period endowments and their distribution. Therefore, even though the allocation of eq. (1) is by itself uncertain (and not only person $i$ 's position in it), we can analyze the maximization problem (2) independently on any other possible realization of social endowments.

Since $V_{j}\left(m, x \mid m^{\prime}, y\right)=v_{j}(m)+u_{j}(x \mid y)$, it is easy to verify, by the concavity of $v_{j}$, that the solution to this optimization problem implies $m_{1}=\cdots=m_{n}=$ $\bar{m}^{\prime}=\frac{1}{n} \sum m_{j}^{\prime}$. For the optimal values of the $x$ good, person $i$ sets the values $x_{i}^{*}$ and $x_{i_{*}}$ such that

$$
x_{j}\left(\omega_{j}\right)= \begin{cases}x_{i_{*}} & y_{j} \leqslant x_{i_{*}} \\ y_{j} & x_{i_{*}}<y_{j}<x_{i}^{*} \\ x_{i}^{*} & y_{j} \geqslant x_{i}^{*}\end{cases}
$$

where

1. $\sum_{j: y_{j} \leqslant x_{i_{*}}}\left(x_{i_{*}}-y_{j}\right)=\sum_{j: y_{j} \geqslant x_{i}^{*}}\left(y_{j}-x_{i}^{*}\right)$.

2. For $y_{j}<x_{i_{*}}$ and $y_{j}^{\prime}>x_{i}^{*}, u_{i}^{\prime}\left(x_{i_{*}} \mid y_{j}\right)=u_{i}^{\prime}\left(x_{i}^{*} \mid y_{j}^{\prime}\right)$. Denote this common derivative $d$.

3. For $y_{j} \in\left[x_{i_{*}}, x_{i}^{*}\right], u_{i}^{\prime}\left(y_{j}^{-} \mid y_{j}\right) \geqslant d \geqslant u^{\prime}\left(y_{j}^{+} \mid y_{j}\right)$.

The first condition, which follows directly from the first constraint, implies that the net transfer of the non-money good is zero. The second condition suggests that person $i$ would like his marginal utility from this good to be the same for all those cases where his ultimate allocation will be different from his second period initial endowment. This is an obvious condition, since for these cases the utility function $u_{i}$ is differentiable at his outcome. (Of course, the fact that for all $y_{j}<x_{i_{*}}$, the derivative $u_{i}^{\prime}\left(x_{i_{*}} \mid y_{j}\right)$ is the same follows by the third assumption we made concerning the nature of the function $V$ ). The third condition states that for those cases $j$ where his endowment does not change, the common marginal utility of the rest of the cases $d$ must be between his marginal utility from loss and the marginal utility from gain at $y_{j}$. Obviously if this condition is violated, (say, $d$ is above the marginal utility from loss at $y_{j}$ which is between $x_{i_{*}}$ and $x_{i}^{*}$ and will therefore not change), then it would be better for person $i$, in terms of expected gains and losses of utility, to have less of the non-money good if $y_{j}$ is its realization, and to have 
more of it in the cases where the above conditions imply that the marginal utility from it is $d$.

Observe that the second and the third conditions are obtained with respect to $u_{i}^{\prime}$, the derivative of the utility function of person $i$, and not with respect to the marginal utilities of all individuals. As in the previous section, we assume that person $i$ knows his identity (and hence, his utility function), but is uncertain what bundle he will initially own in the second period.

As before, the desired result for the reallocation of money can be obtained by a simple majority rule. But the same rule will take too many units of $x$ from the rich and transfer them to the poor. Clearly, individual $i$ would like in period 1 to entrench the property rights of those whose future $x$ endowment will be less than $x_{i}^{*}$, which is of course larger than the average quantity of $x$, $\bar{x}$.

Two conclusions follow immediately from this analysis. First, money and land need different entrenchments. Note that given the additively separable structure of the functions $V_{i}$, the optimal entrenchment of each of the two goods is independent of the actual entrenchment of the other. Secondly, simple majority is not enough to offer the kind of protection for property rights of land individuals living in period 1 want for the future. Suppose that under all circumstances society agrees that if any plot of land is to be transferred, then it should be transferred from those who have more to those who have less. Then even those individuals whose endowment is not threatened, will agree to such reallocations. The simplest way to prevent "too much" land from being reallocated, that is, to prevent taking from a rich person $j$ more than $y_{j}-x^{*}$, is by imposing a super majoritarian rule. Of course, the optimal values of $x^{*}$ and $x_{*}$ depend on the utility functions $u$, on society's future endowments, and on their allocation. Since individual utilities and individual beliefs regarding these eventualities may differ, so will the optimal values of $x^{*}$ and $x_{*}$ differ from one person to another. But all members of society will agree that more than a simple majority is needed to expropriate land from their future possessors in order to benefit other members of society.

We conclude this section with a numerical example. We assume here that there is only one possible allocation of second period endowments, and the only source of uncertainty relates to the identity of the different individuals in this allocation. 
Example 1 Let $n=3$, and suppose that all three individuals have the same utility function $V\left(m, x \mid m^{\prime}, y\right)=v(m)+u(x \mid y)$, where $u(x \mid y)$ is given by

$$
u(x \mid y)= \begin{cases}\sqrt{x} & x \leqslant y \\ \frac{1}{2}[\sqrt{x}+\sqrt{y}] & x>y\end{cases}
$$

Suppose $y_{1}=1600, y_{2}=1200$, and $y_{3}=900$. Clearly, $u^{\prime}\left(y_{1}^{-} \mid y_{1}\right)=\frac{1}{80}$ while $u^{\prime}\left(y_{3}^{+} \mid y_{3}\right)=\frac{1}{120}$. There is therefore no reason for individuals in period 1 to wish to have any transfers of land in the second period. On the other hand, if $y_{1}=4900$, then $u^{\prime}\left(y_{1}^{-} \mid y_{1}\right)=\frac{1}{140}$, and following our analysis, individuals in the first period would like future society (that is, the second period society) to transfer land from the rich to the poor. It is easy to verify that the optimal amount of land transferred is 260 .

\section{Example: The American Constitution}

In this section we discuss two fundamental legal doctrines that seem to be consistent with our analysis. The discussion is intended to shed some new light on the analysis of property protection in American Constitutional Law.

\subsection{Constitutional Protection of Property Rights}

The Fifth Amendment to the American Constitution provides that "no person shall be ... deprived of ... property without due process of law; nor shall private property be taken for public use, without just compensation." The first part of the cited passage could be interpreted as a constitutional entrenchment of all forms of wealth, but in reality it is not so interpreted. The most straightforward method of wealth redistribution, direct taxation, is obviously not banned by the constitution, and is commonly practiced with the avowed purpose of taking from the rich and giving to the poor. ${ }^{8}$ The second

\footnotetext{
${ }^{8}$ If the purpose of taxation is to provide government funding of public goods, taxpayers do get some return for their tax dollars; but even in this case there is a clear repudiation of the quid pro quo philosophy as many taxpayers are contributing more than their share in the funding of the common good.
} 
part of the cited passage, commonly referred to as the "Taking Clause," stipulates that property cannot be taken without due compensation. ${ }^{9}$ Why can the government tax the general resources of taxpayers, without compensating them for their losses, but it is banned from doing so if the object of its intentions falls within the ambit of the Taking Clause? One obvious distinction is that "taking," unlike taxation, is never practiced on money or other tradable goods. It is practiced on real objects, and most commonly on land. "Taking" forces people to part with endowed objects, while general taxation does not. The analysis of the previous sections suggests that since taxpayers do not endow their overall wealth, wealth redistribution ought to be voted on by employing the simple majority rule. Since property owners do endow, on the other hand, their real estate and other takable assets, a redistribution of these assets ought to be voted on by employing a super majoritarian mechanism.

A further examination of this hypothesis reveals some additional insights. Suppose people did not have money and other tradable goods and all their wealth were invested in endowed objects. If this were the case, general taxation would have destroyed the taxpayers' sense of endowment, because to finance their tax obligations, taxpayers would have to sell their endowed assets. In a situation like this general taxation ought to have been banned as well, unless ratified by a super majoritarian constituency. But at some historical periods this situation was exactly the case. By the end of the 18th century, when the American Constitution was drafted, and for a long time thereafter, a typical portfolio representing the citizens' wealth consisted of tangible assets like land, plantations, and slaves and not of ready cash, corporate securities, and other tradable assets (see [8]). This situation was faithfully mirrored in the constitutional treatment of the subject of general taxation. Although the Constitution, in its original form, declares (Article I, Section 8) that "the Congress shall have Power to lay and collect Taxes, Duties, Imposts and Excises..." it was widely believed that it lacked power to impose a general income tax, and, indeed, it was so held by the Supreme Court. ${ }^{10}$ This constitutional ruling was partly based on some idiosyncratic considerations relating to the American form of federalism, but it was also

\footnotetext{
${ }^{9}$ Although linguistically the Taking Clause is not limited in scope, and could be directed against any form of wealth, in practice it applies mainly to property and not to money.

${ }^{10}$ See, for example, Pollock v. Farmers' Loan and Trust Co. 158 U.S. 601 (1895).
} 
consciously made to reflect a deeply felt antipathy to the redistribution of wealth. Redistribution was bound to generate, in the words of one of the Justices, "the specter of Socialism," and was bound to result in "an assault on capital," which was nothing short of "a war of the poor against the rich." Not until the Sixteenth Amendment, introduced in 1913, did Congress get the power to impose general taxation. There are, of course, other reasons why the Sixteenth Amendment was introduced, which have to do with a shift in the popular understanding of the role of government. However, one cannot ignore the fact that by the second decade of the 20th century it was no longer necessary to sell land and other endowed assets to finance the typical taxpayer's tax bills; ${ }^{11}$ hence the optimal constitutional protection of moneyed wealth became the simple majority rule. A modern day echo of the income tax controversy of a century ago can be found in the debate relating to the estate tax. One objection to this tax centers on the implications of the tax for families who own most of their wealth in endowed assets, like farms, homesteads and a variety of family businesses.

The Taking Clause in itself merits a closer look. When some property is condemned for public use, the language of the Constitution is straightforward and due compensation is promptly paid. But there are many more ways to take something away from someone without expropriating it. The most common form of government interference with ownership is by regulating it away, e.g. by zoning decisions that diminish the value of land. Arguably, there should be little difference between, say, taking $50 \%$ of someone's land for the purpose of constructing a railroad track, and rezoning an area in a way that reduces the value of all affected real estate by $50 \%$. From a doctrinal perspective, however, there is a great deal of difference. A few years after the passage of the 16th Amendment, the Supreme Court ruled that mere regulation is not "taking," 12 although in extreme cases, where the effects of the regulatory measure are indistinguishable from straightforward condemnation for public use, regulation could be tantamount to "taking."

For example, in one case, ${ }^{13}$ the Supreme Court held that a zoning decision turning parts of Penn Central Station in New York into a city landmark, which severely limited its owners' freedom to develop their own real estate,

\footnotetext{
${ }^{11}$ For the distribution of wealth between financial and tangible assets, see Goldsmith [8].

${ }^{12}$ The taking-regulation distinction was articulated in Pennsylvania Coal Co. v. Mahon, 260 U.S. 393 (1922).

${ }^{13}$ Penn Central Transportation Co. v. New York City, 438 U.S. 104 (1978).
} 
was not a "taking." In another case, ${ }^{14}$ the owners of real estate were forced to give the public a right of way on their property as a condition for granting them permit to expand their house. The Supreme Court held that this amounted to "taking." The apparent contradiction between these two outcomes has puzzled commentators for a long time. In conformity with our main argument it can be pointed out that in the first case the possession of the regulated area remained in the hands of its owners. The detrimental regulation merely affected its monetary value and therefore did not violate the owners' sense of endowment. In the second case, the effect of the regulation was to condemn endowed assets and to convert them into public use. The owners could no longer enjoy exclusive possession of a strip of land on which the public had a right of way.

\subsection{Contractual Freedom}

Another major shift in the doctrinal attitude to property rights occurred in relation to contractual freedom. To what extent are firms free to contract with labor for oppressive work conditions (say, extremely long shifts, unrestrained work conditions for underage employees, or a ban on organization and unionization)? To what extent are firms free to exploit market conditions in their favor without constraint (for example, set "excessive" prices or flood the market with substandard products or services)? The privilege of doing so, and the correlative duty of the other party to abide by such stipulations, is an important property right of firms, and one that was largely immune from majoritarian (that is, statutory) interference well into the 20th century. Thus, in the well known case of Lochner v. New York (198 U.S. 45 (1905)) the Supreme Court struck down, on constitutional grounds, a state statute purporting to limit the maximum working hours for bakers. It was held that such a statute infringed the right of the employer and the employee to freely negotiate and forge their own agreements exactly as they wished. Many similar statutes (some 200 of them) were held unconstitutional during the so-called Lochner era. ${ }^{15}$ The turning point did not occur until the

\footnotetext{
${ }^{14}$ Nollan v. California Coastal Commission, 483 U.S. 825 (1987).

${ }^{15}$ The identification of the Lochner style doctrine of contractual freedom with the allocation of property rights, and thus of political power, to the rich at the expense of the poor, has become a major tenet of the critical legal studies movement. See Horwitz [9].
} 
mid-1930's, when Lochner was reversed and contractual freedom lost its independent constitutional immunity. ${ }^{16}$

A straightforward explanation of the post Lochner jurisprudence is by direct reference to the New Deal philosophy, which turned its back on laissez faire economics and embraced a regulatory approach instead. Nor did the post Lochner justices have much of a real choice in this matter, given President Roosevelt's threat to restore majoritarianism by packing the Supreme Court. Here we add another explanation. In 1933, Berle and Means [3] introduced the idea that corporate ownership and corporate control became, for all practical purposes, separated from each other. This peculiarity is not typical of other forms of wealth (land, machinery, intellectual property) and it was a new apparition on the corporate scene as well, since most 19th century enterprises were essentially family businesses. Clearly, there is a difference between owning a controlled enterprise (a closely held corporation) and holding a financial stake in a publicly held firm. One does endow a close corporation (alongside with whatever the company possesses) as "one's own." 17 On the other hand, one presumably treats financial assets in public firms according to their true nature, as fungible, tradable units of wealth. Like cash, corporate securities do not create in their owners any noticeable endowment effect (see Footnote 2 above). In protecting the firm's right to contractual freedom, the Lochner era courts recognized the entrenched status of endowed wealth. In the later repudiation of that entrenched status, the post Lochner courts were simply subjecting unendowed forms of wealth to the rigors of majoritarian democracy.

Other examples for the difference between legal protection of endowed assets and financial assets can be found in various insolvency statutes, which typically exempt debtors' homesteads from the reach of their creditors. Some wages are exempt as well, but to a dramatically lesser extent. Another

\footnotetext{
${ }^{16}$ For example, in Nebbia v. New York, 291 U.S. 502 (1934), the Supreme Court upheld, for the first time, the right of state legislatures to fix maximum or minimum prices (in this particular case the commodity in question was milk containers). Later on, the court took even a more extreme position. In Williamson v. Lee Optical Co., 348 U.S. 483 (1955) the Court upheld a state statute regulating opticians away from the frame fitting business. This was done to accommodate the interests of the ophthalmology profession; the court reached this outcome although it did not endorse the policy behind the statute and even considered it detrimental.

${ }^{17}$ For the law's detailed response to the sense of endowment in close corporations, see, for example, O’Neal [13].
} 
example is the fact that when debtors collateralize an asset as security for a debt, they always enjoy the so-called "equity of redemption," meaning that regardless of any agreement to the contrary, a debtor has an option to redeem the collateralized asset in priority to all other persons.

\section{Some Additional Clarifications}

In this section we discuss some possible objections to our analysis.

WhAT SUPER MAJORITY? This question concerns the identification of the ideal super majority. We did show that the redistribution of wealth ought not to be conducted by using the simple majority rule, but we failed to identify what kind of super majority to employ. Our model is not rich enough to answer this question. Using the notations of Section 3, each member of society has an individual value for $x^{*}$, the lower boundary below which property is not to be seized, which depends on the individual's utility function and on his beliefs regarding future endowments and their distributions. As before, denote these personal values $x_{i}^{*}$. For each such value there is a corresponding size of super majority, given by the proportion of future endowments that are below $x_{i}^{*}$. If society were to select by voting a particular super majority rule, then a simple majority would presumably choose the median value of these individually-optimal super majority rules. There is no logical inconsistency in a simple majority entrenching future rights by requiring a super majority, as everyone in our model wants some super majoritarian defense for future reallocations. ${ }^{18}$

Clearly, the more concave the individuals' utility functions are, the greater is the justification for an egalitarian distribution, which can best be achieved by weaker super majoritarian prerequisites. On the other hand, the fonder are the members of a given society of their initial endowments, the greater is the need for a stronger constitutional entrenchment. Each society may have its special traits with regard to these two parameters, and may well need its own custom-made majority rule.

\footnotetext{
${ }^{18}$ Incidentally, this insight lays to rest a common objection to constitutional entrenchment of entitlements which is obtained by a bare majority of the voters; the bare majority relates to the particular super majority selected by the constituency, but the very principle of super majoritarian entrenchment enjoys a universal support.
} 
What IS THE ENDOWment? Consider again the utility functions of Example 1. After 260 units are transferred from person 1 to person 3, their corresponding wealth levels become 4640 and 1160. Should these numbers be now used as the new endowments and should the calculations now be done again with respect to these wealth levels?

We don't have a general answer to this question, but given our assumptions, the question is irrelevant. In Section 3 we assumed that for every $i$ and for $x<y<y^{\prime}, u_{i}(x \mid y)=u_{i}\left(x \mid y^{\prime}\right)$, and for $x>y>y^{\prime}, u_{i}(x \mid y)=$ $u_{i}\left(x \mid y^{\prime}\right)+\left[u_{i}(y \mid y)-u_{i}\left(y \mid y^{\prime}\right)\right]$. In our example it is indeed the case that $u_{1}^{\prime}\left(4640^{-} \mid 4640\right)=u_{1}^{\prime}(4640 \mid 4900)$, and $u_{3}^{\prime}\left(1160^{+} \mid 1160\right)=u_{3}^{\prime}(1160 \mid 900)$. There is therefore no need to transfer any more land from person 1 to person 3 .

This third assumption implies that the dependency of the marginal utility at $x$ on the endowment $y$ relates only to whether $x$ is above or below $y$. For all levels of $y$ below $x$, the marginal utility at $x$ is the same, and the same holds true for all levels of $y$ above $x$. Of course, these two levels are different. ${ }^{19}$

Why DOESN'T SOCIETY REDISTRIBUTE WEALTH ABOVE $x^{*}$ ? Given the fact that the poor outnumber the rich, one wonders why doesn't a simple majority of the voters redistribute all moneyed wealth equally among the entire population, and why doesn't a special majority redistribute at least some of the endowed wealth. Egalitarian redistribution is not a reasonable alternative because of the negative incentives it creates. The voters realize that it might be better to get a smaller percentage of a larger pie than the other way around. With this said, a lot of money distribution, and a fair amount of property redistribution, takes place through tax transfers. The object of taxation is money, but financing it often requires a marked diminution of endowed assets. Finally, one must not underestimate the vigor of the existing constitutional entrenchment. Consider once more the American example. Securing a majority vote of two thirds in the House, two thirds in the Senate and ratification by $75 \%$ of the states (where every state imposes its internal super majoritarian requirements) is almost tantamount to imposing a constraint of unanimity.

\footnotetext{
${ }^{19}$ Sunstein [17] seems to have the opposite intuition. He appears to claim that once the endowment structure is altered, all individuals develop a new allegiance to the new structure, and thus there is no good reason to be opposed to judicial review, which tends to overrule the original sense of endowment.
} 


\section{References}

[1] Atkinson, A.B. 1983. The economics of inequality, 2nd ed. Oxford: Clarendon Press.

[2] Bateman, I., A. Munro, B. Rhodes, C. Starmer and R. Sugden. 1997. A test of the theory of reference-dependent preferences. Quarterly Journal of Economics 112:479-505.

[3] Berle, A.A. and G.C. Means. 1933. The modern corporation and private property. New York: Macmillan.

[4] Black, C. 1999. A New Birth of Freedom. New Haven, CT: Yale University Press.

[5] Buchanan, J.M. and G. Tullock. 1962. The calculus of consent, logical foundations of constitutional democracy. Ann Arbor: University of Michigan Press.

[6] Cooter, R. 2000. The Strategic Constitution. Princeton: Princeton University Press.

[7] Harsanyi, J.C. 1953. Cardinal utility in welfare economics and in the theory of risk-taking. Journal of Political Economy 61:434-435.

[8] Goldsmith, R.W. 1985. Comparative national balance sheets. Chicago: University of Chicago Press.

[9] Horwitz, M. 1992. The Transformation of American Law 1870-1960: The Crisis of Orthodoxy. New York: Oxford University Press.

[10] Kahneman, D. and A. Tversky. 1979. Prospect theory: An analysis of decision under risk. Econometrica 47:263-291.

[11] Knetsch, J.L. and J.A. Sinden. 1984. Willingness to pay and compensation demanded: Experimental evidence of an unexpected disparity in measures of value. Quarterly Journal of Economics 99:507-21.

[12] Olson, Mancur. 1971. The Logic of Collective Action. Cambridge, Mass.: Harvard University Press. 
[13] O’Neal, H., and R. Thompson. 2000. Close Corporations. St. Paul, MN: West Group.

[14] Przeworski, A. 1971. Democracy as a contingent outcome of conflicts. In J. Elster and R. Slagstand (eds.): Constituionalism and Democracy, pp. 59. Cambridge: Cambridge University Press.

[15] Rawls, J. 1971. A Theory of Justice. Cambridge, Mass.: Harvard University Press.

[16] Strauss, D. 2001. The irrelevance of constitutional amendments. Harvard Law Review 114:1457-1505.

[17] Sunstein, C. 1993. The Partial Constitution. Cambridge, MA: Harvard University Press.

[18] Thaler, R. 1980. Toward a positive theory of consumer choice. Journal of Economic Behavior and Organization 1:39-60.

[19] Tullock, G. 1988. The calculus-postscript after 25 years. In J. Gwartney and R. Wagner, (eds.), Public Choice and Constitutional Economics pp. 139. Greenwich, CT: JAI Press.

[20] Tushnet, M. 1984. An essay on rights. Tex. L. Rev. 62:1363-1403.

[21] Tversky, A. and D. Kahneman. 1991. Loss aversion in riskless choice: A reference-dependent model. Quarterly Journal of Economics 106:10391061 .

[22] Tversky, A. and D. Kahneman. 1992. Advances in prospect theory: cumulative representation of uncertainty. Journal of Risk and Uncertainty $5: 297-323$. 